\title{
The Plaid Fabric Application in Fashion Women's Clothing
}

\author{
Peng Yu
}

Design and Management Department in Jiangxi Institute of Fashion technology Nanchang Jiangxi 1013834970@qq.com

\section{Keywords: Plaid Fabric; W Fabric; Oundstooth; Othing Aesthetics}

\begin{abstract}
This article discusses the use of plaid fabric fashion ladies. Taking into account the specific characteristics of the new fabrics, the paper analyzes the application of new and old plaid fashion design, aims to promote the application of plaid fabrics in fashion couture. Herein by reference, in a certain sense Plaid fabric costume design direction, focusing respected plover.
\end{abstract}

\section{Introduction}

Overview. With the development of time, most people have a higher quality of family life pursuit. As early as 70s, checkered cloth is mainly used for private school uniforms and retro furniture. Today, the lattice can be developed in clothing, shoes, purses and wallet, to name a few. From the mass market to fashion, the entire grid everywhere was suddenly, Even the Marc Jacobs shorts on the track it. Of course, the grid can be used for Christmas stockings and uniforms! It shows a bright future. Many fashion brands have already entered this field. More rigorous lattice patterns can be used for more complex pants, a more daring, larger model can be used for dresses and shirts, which are often used to have a pair of sparkling money grid cloth during holidays. Flannel grid fabric is often used to hunt and winter. Originally, plaid is made of linen and wool, but now you can find the plaid in the application of any textile (even)!. Plaid fabric is very suitable for any project, the need for a eternal, chic, or weird. And chequered with sisters feelings plover case grain also is a kind of classic flavor restoring ancient ways is popular element. And tend to be more fashion women's clothing industry. Important elements of modern garment design theory agree with fabric.

Clothing aesthetics. In a sense, is the clothing design, the perfect development of the aesthetic characteristics of the fabric. Clothing development history also proves that the reform of materials, often brings new opportunities and vitality, resulting in changes in fashion, promotes the development of the garment industry. Fashion women's design is no exception. Therefore, the use of the grid fabric fashion design becomes a weapon.

\section{The Relationship between Clothing and Fabrics, Clothing Development}

Everyone wants to dress up in the latest fashion and style of clothing. In fact, no one wants to wear something that is out of date, completely out of style. Dress up at the forefront of fashion, you have to know what the modern style of clothing is, and how you can put these styles in your wardrobe. Fashion is very changeable, the myriads of changes. What may be regarded as today's modern clothing style may not be in the second day, this is the costume design.

Fashion design is the application of art design and aesthetics or natural beauty clothing and clothing. Fashion design is generally believed to have started in nineteenth Century! Charles Frederick Voss, who was the first designer to have his label sewn into the clothes he created. Clothing design and creation of the handling of a large extent is not signed by the tailor, senior fashion is worn on the body of the royal court Hou Yi.

\section{Clothing Ideas of Reform, Updated Grid Garment Fabric}

The key to improve the design of apparel fabrics and garments is creative masters. From ancient times to the present, people change their clothing aesthetics, clothing fabrics will be more or less affected. Japanese fashion designer Issey Miyake (Issey Miyake) has a unique clothing focus, 
decided to learn from the Western culture and the wonderful fusion of Eastern culture, to explore new elicitation; He first applied the design of tiny structures, ordered, tightly pleated fabric. The use of this fabric has become a popular symbol of the world's deconstruction of fashion

Fold the fabric made of clothing has a special appearance, this is the proper moderately loose, lighten the all eyes. It soon became a symbol of people pursuit of freedom and comfort.

The world famous fashion brand BURBERRY, in 1924 registered a new brand trademark logo: plaid. This red, white, black, light brown grid composed of four patterns, was BURBERRY used in the windbreaker lining, and later became almost synonymous with BURBERRY, which is the world's most representative of the grid fashion brand. While the lattice of representatives of thousands of birds will be grid. Duke of Windsor is the first to wear its celebrity, celebrity effect; this tweed pattern has become the nineteenth century, twentieth Century British aristocracies favorite. The earliest to thousands of birds on the fashion stage, and get the top of the noble elegance of the top of the Christian Dior, Dior in 1948 will optimize the combination of canine teeth pattern used in the perfume box, also gave it a Enough to the good name of the immortal world thousands of birds. After the fashion industry has been widely used, get out of hand.

\section{The Appearance of the New Clothing Fabric-Driven Clothing Style Changes}

The rapid development of science and technology has brought about unprecedented changes. Many countries are developing new fiber-rich fiber resources. In new textile fabrics often appear. All kinds of lattice fabric updates, Provide clothing material basis and guarantee of prosperity, every outstanding costume design pays attention to the latest apparel fabrics, design space recognition and grasp from new fabrics more widely.

As the world's leading fashion clothing company, BURBERRY Company in the design and production, fabric flexibility has been greatly improved. The British tradition of the noble design, to win the favor of countless people to become an eternal brand. At the same time, has been a dazzling high-end women's pronoun Christian Dior. His choice of high-end gorgeous, superior fabrics to show dazzling, dazzling gorgeous and elegant women's clothing, much attention to the fashion industry. He inherited the tradition of the French high women, always maintain a high-level gorgeous design line, fine workmanship, to meet the upper-class mature women's aesthetic taste, a symbol of the highest spirit of French fashion culture, Dior brand in Paris high status, Of the fabric is also emerging in its fashion clothing, spread to each material of the new fabric. The new style of clothing fabrics help power to a large extent affected. Thinner and lighter Western traditional clothing fabrics are gradually changing the strong outside, become more soft and comfortable.

\section{In The Design of the Lattice Fabric Factor}

If you are looking for a modern feminine costume design to discuss any further, we have female clothing divided into two categories. One is the day and evening wear. Day wear will include support; you can wear to go to work can also wear casual wear, dinner with friends. Work wear some pants a few years ago the monotonous suit or skirt women. But modern women wear work style fashion has become more fashionable and chic. Large customizable suits, worn panniers and satin blouses are great professional women's clothes that can be worn to the conference room. Dress in neutral tones skirt, just hit your knees is the appropriate modern fashion style office. In order to give your work a modern flavor, do not be afraid to try the color. Just because you are going to work, does not mean you need to look boring and monotonous. Dark blue, deep purple and chestnut plaid shirts should be incorporated into your office in the form of either accessories or a shirt or trim. These bold colored grids give you a little jazz and any gear that makes you look great.

Hedging the shortening of the fashion cycle, the improvement of science and technology, and the intense competition between the industries, the fabric tends to be more colorful, it provides a vast space for designers. The main prerequisite is beautiful and comfortable, it should make people feel very comfortable, and that is comfortable to wear, looking at also comfortable. Second, market research shows that while the traditional plaid as the main fabric, they are too crowded in 
low-income and medium-sized markets. To take high-end market, which is to master the fashion trend of the fabric?

\section{Lattice Fabric Comfort Factor}

Lattice pattern is a relatively special pattern with cotton. Comfort is the fundamental factor. With the constant demands of people's clothing, they want to enjoy the special pleasure and relaxation at any time. Therefore, in the choice of fabric, we usually like the skin-friendly type. Knitting even better than the fabric. Elastic fabrics are better than non-elastic fabrics. Although not all lattice fabric clothing must be close to the skin, but gives the first impression, visual and tactile aspects, must give a very comfortable. Of course, the direct lifting of the skin type of lattice clothing, such as underwear, pajamas, etc., but also to comply with state regulations. National fiber inspection standards in 2013 is provided, all direct contact with the skin class (including 0-3 year-old children's clothing) clothing, must comply with Class A standard.

With the continuous upgrading of cotton, people are seeking to give new products more and more technology. Cotton fabric cannot meet people's needs. Cotton woven fabric, the green environment-friendly fabrics, functional fabrics have become the new darling of the clothing designers. But the grid pattern of fabric has not left the people's attention.

\section{Fabric of the Epidemic Factors}

Clothing and the popularization of the fabric, is a unified subject. The popularity of the fabric and changes in the clothing style, costume design, but also has an irreplaceable motive. Fashion designers should pay attention to the latest fabric information to understand the fashion industry trends, including the fabric material and pattern, in time to determine and adjust the fashion fabric design according to the fabric. As the fashionable predictors discuss next season's colors, they always take color, pattern, and other factors into account. In some cases, the popularity of apparel reflects the changes in apparel fabrics and technology. For example, we design summer dress dresses, ladies, we should know that natural colored cotton, clean silk, and new green fabric is now the main fabric of summer fashion. Fabric should have the gentle cotton patterns, warm and bright little flowers, and the classic plaid. In these popular fabric design, based on the designer can better grasp the fashion trend.

\section{The Use of New Fabrics and Traditional Designs of Clothing Design}

Bamboo Fiber Fabric in the Use of Clothing Design. Bamboo fiber is one of the re-made fibers. Bamboo made of high-tech means. Bamboo fiber can tolerate hard grinding, no lint, moisture absorption and breathability. Feel soft and cool. People's clothes made of bamboo fiber will be more comfortable. In addition, bamboo fiber anti-virus type and environment-friendly, bright color porcelain, to meet people's needs today. Made of bamboo fiber, can provide a comfortable feeling, anti-virus, prevent skin diseases. Taking into account these characteristics, bamboo fiber is the right choice of spring and summer clothing design materials. Combined with the traditional grid pattern form, the color with the new, in line with people's comfort at the same time, better meet the human visual senses, which is a good grid pattern role. Can also be summarized into a simple series of colors, inherited the nature of bamboo. Woven, knitted, or jacquard fabrics are good choices. Design should be simple, taste good. Different cut, you can make clothing style discarded clothing fabric there is a big difference, but also in a series of coexistence of great harmony. Designed in the designer clothing, made of new materials, can be used to fold or thousands of birds and other patterns, increase the level of clothing, make it more attractive to consumers eye. 


\section{The Design and Application of the Chimp Geiger in the Sweater Garment}

Sweater clothing in the domestic market share is only 20\%, while many European countries or the Americas market share of sweaters has been about four percent. Sweater refers to the wool or cashmere or chemical fiber yarn knitted garments, knitted garments because of sweaters with fabric type of woven fashion in the cutting and craft making when there is a big difference, so give the lattice pattern In particular, thousands of birds are very large space for development. Sweater, knitted from cashmere as raw materials, clothing, and cashmere sweater category is the most valuable, full and delicate shape, soft and smooth waxy touch, wearing light and comfortable, warm and good, both inside and outside wearing Safe. Domestic production of the most advanced knitted garments on the number of German STOLL computer flat knitting machine, knitted garments in the production process, the use of computer production, so the size of the grid and the arrangement of birds are not charged, as long as the designer can make to improve the effect of plans, computerized flat knitting machine can basically be completed. Ordos, like the domestic knitting industry ranked first in the cashmere sweater, are used in these processes and machines, and then the basic pattern is also able to do it cumbersome, but the market is very good. Invisible Thousands of birds into the grid to a higher height, visibility and better access to universal validation. In short, to allow the market to verify, are good fashion design.

\section{Conclusions}

As people's living conditions improving, more and more people have a higher pursuit of fashion, self-confidence, personality, elegance, quality, and respect for the classic, has become a way of life. As a result, the demand for home clothing gradually heating up, the pursuit of the classic wave of wave pattern of wave pattern. They are more demand for high-quality more personalized fashion classic clothing. It's a crucial factor that using reasonable and proper lattice fabric and patterns, not only to make the whole dress looks more quality and more personality, but also for clothing itself to a greater degree of value release. This is an excellent clothing brand to conquer and master the important factors in the market.

\section{Acknowledgements}

The educational reform in Jiangxi Province in 2015 "task driven teaching method in the" CoreIDRAW "clothing computer curriculum research and application" stage results, project number: JXJG15-26-5

\section{References}

[1] X.X Zhang, Origami elements in the design of the use of clothing [D]. Beijing Institute of Clothing 2010

[2] F.F Chi, Visual fantasy pattern in the application of clothing design [D]. Beijing Institute of Clothing 2010

[3] T.Shu, "College" fashion design style [D]. Beijing Institute of Clothing 2010

[4] F.Yu, Stripes in the costume design of the factors [D]. Suzhou University 2008

[5] H.Q Li, on the pattern in the costume design of the decorative features [D]. Suzhou University 2008

[6] D.K Wang .Chinese traditional clothing pattern research and application in modern clothing design [D]. Suzhou University 2008

[7] Y.T Li, Modern clothing designs in the application of traditional clothing elements [D]. Tsinghua University 2007

[8] J. Li, Apparel design in the use of clothing design [D]. Suzhou University 2007 
[9] W. Xie, Lattice pattern in the textile design [D]. Donghua University 2007

[10]D. Wang, Han Mei.Application of Grid Pattern in Costume Design [J] .Journal of Technological Innovation 2007 (31) 